\title{
Standardisation and comparison of serial dilution and single dilution enzyme linked immunosorbent assay (ELISA) using different antigenic preparations of the Babesia (Theileria) equi parasite
}

\author{
Sanjay KUMAR ${ }^{\mathrm{a} *}$, Yogesh KUMAR ${ }^{\mathrm{a}}$, Dharam V. MALHOTRA ${ }^{\mathrm{a}}$, \\ Shruti DHAR ${ }^{\mathrm{b}}$, Anil K. NICHANI ${ }^{\mathrm{b} * *}$ \\ ${ }^{\mathrm{a} D e p a r t m e n t ~ o f ~ V e t e r i n a r y ~ E p i d e m i o l o g y ~ a n d ~ P r e v e n t i v e ~ M e d i c i n e, ~ C o l l e g e ~ o f ~ V e t e r i n a r y ~ S c i e n c e s, ~}$ \\ CCS Haryana Agricultural University, Hisar 125 004, Haryana, India \\ ${ }^{b}$ All India Coordinated Research Project on Blood Protista, College of Veterinary Sciences, \\ CCS Haryana Agricultural University, Hisar 125 004, Haryana, India
}

(Received 26 December 2001; accepted 16 July 2002)

\begin{abstract}
Serial dilution and single dilution enzyme linked immunosorbent assays (ELISA) were standardised and their sensitivity and specificity were compared for serodiagnosis of Babesia equi infection. The antibody titres of 24 donkey sera of known identity were determined separately by serial dilution ELISA using three different $B$. equi antigens namely whole merozoite (WM), cell membrane (CM) and high speed supernatant (HSS). The ratios of the optical density (OD) of known positive and known negative sera at different serum dilutions were calculated and termed as the positive/negative $(\mathrm{P} / \mathrm{N})$ ratio. The coefficients of correlation (r) were calculated between the $\mathrm{P} / \mathrm{N}$ ratios at different dilutions of sera and the $\log _{10}$ antibody titres of the same sera were ascertained by serial dilution ELISA. The highest value of ' $r$ ' was obtained at a serum dilution of 1:200. From $\log _{10}$ antibody titre of sera $(\mathrm{y})$ and their $\mathrm{P} / \mathrm{N}$ ratio at a dilution of 1:200 (x), regression equations $(\mathrm{y}=\mathrm{a}+\mathrm{bx})$ were calculated separately for the three antigens. Test sera were diluted to 1:200, their OD were read in duplicate wells and were converted to the $\mathrm{P} / \mathrm{N}$ ratio. Antibody titres were predicted from the $\mathrm{P} / \mathrm{N}$ ratio using a regression equation separately for the three antigens. Titres obtained by both ELISAs were not significantly different from each other, thus confirming that single dilution ELISA could be successfully used to replace conventional serial dilution ELISA. The sensitivity, specificity and predictive value of single dilution ELISA was validated statistically using $42 \mathrm{~B}$. equi diseasepositive sera and 106 B. equi disease-negative sera. The WM antigen was found to be the most sensitive with a higher predictive value for negative test sera as compared to the CM or HSS antigens. Sera positive for other equine infections including Babesia caballi showed no cross-reaction with the three $B$. equi antigens in ELISA, thus the test was immunologically specific. Antibody titres of 109 unknown field donkey/horse sera obtained by serial and single dilution ELISA using the WM antigen did not show any significant difference. Since the single dilution ELISA was found to be
\end{abstract}

\footnotetext{
*Correspondence and reprints

Fax: (81) 15549 5643; e-mail: sanjayk2002@hotmail.com

Present address: National Research Centre for Protozoan Diseases, Obihiro University of Agriculture and Veterinary Medicine, Obihiro 080 8555, Hokkaido, Japan.

**Present address: Veterinary Infectious Disease Organization, 120 Veterinary Road, Saskatoon, SK, S7N 5E3, Canada.
} 
more economical, convenient, sensitive, specific than the serial dilution ELISA and has a high predictive value, it is suitable for use in sero-epidemiological studies on $B$. equi infections in the field.

Babesia equi / Theileria equi / protozoan / sero-diagnosis / ELISA

\section{INTRODUCTION}

Equine babesiosis is an acute, subacute or chronic tick-borne disease of the equidae (horse, pony, donkey, mule and zebra), caused by the intraerythrocytic protozoan Babesia (Theileria) equi and/or Babesia caballi. Babesia equi and B. caballi share the same vectors, but in an enzootic region $B$. equi is reported to be more common than $B$. caballi [20]. The disease has attained worldwide importance due to the widespread prevalence of associated tick vectors [4]. Equine babesiosis caused by B. equi is endemic in India, but only isolated clinical cases have been reported $[26,27]$. However, outbreaks of the disease have also been reported when clean animals are introduced into endemic zones [12].

Diagnosis of the disease can be made on the basis of clinical signs and demonstration of B. equi / B. caballi organisms in blood smears. However, serological tests are required for diagnosis in latent or carrier animals. A number of techniques have been used to measure $B$. equi antibodies in carrier animals. The complement fixation test (CFT) is the test recommended by the Office International des Epizooties (OIE) for the detection of the Babesia species antibodies, combined with IFAT in doubtful cases. These two tests have been used by various researchers $[14,22,30]$. However CFT has the inherent disadvantages of giving false positive results and low sensitivity for detecting latent infections $[6,18$, 19, 25]. Various forms of ELISA have been standardised and are reported to be more sensitive than CFT $[6,18]$. However the cost per sample of ELISA is high and it is tedious and inconvenient when the titre of a sample is to be determined. Recently, single dilution ELISAs have been standardised and used for the sero-diagnosis of the foot and mouth disease [33], bovine babesiosis [1], Pasteurella multocida infection in buffaloes [17] and tropical theileriosis in cattle $[17,24]$. In conventional serial dilution ELISA, the end titre of a sample is calculated by serial two fold dilution of the sample until the optical density (OD) becomes negative. However in single dilution ELISA, only one particular dilution of the serum sample is tested (that is why it is named the single dilution ELISA). The OD value of the one dilution tested is used in the regression equation for predicting the end antibody titre. So single dilution ELISA is less cumbersome, more economical in terms of consumption of antigen/conjugate/reagents and suitable for field studies $[17,28]$ since the titre of a serum sample can be predicted by testing it at only a single dilution. The estimation of exact antibody titres by single dilution ELISA during sero-epidemiological surveys would help in avoiding the movement of naïve horses into endemic regions. We describe here the standardisation of a serial dilution ELISA for detecting antibodies against $B$. equi using three antigenic preparations. The assay was then adapted to a single dilution ELISA format.

\section{MATERIALS AND METHODS}

\subsection{Parasite antigen}

A healthy donkey, negative for B. equi parasites by blood smear examination and negative for B. equi antibodies by DotELISA was obtained and maintained under 
tick-free conditions. The donkey was also serologically negative for Trypanosoma evansi and glanders. The donkey was splenectomised as described by Dennig and Brocklesby [7] and injected with $50 \mathrm{~mL}$ of blood collected in an acid citrate solution $(3.5 \% \mathrm{w} / \mathrm{v})$ from a known B. equi carrier animal, which was continuously maintained in the laboratory. When the parasitaemia reached about $80 \%$ in the donkey, blood was collected in EDTA bottles $(1.2 \mathrm{~g} / \mathrm{L}$ of blood) and was processed for preparation of antigens as described by Brown et al. [5]. Briefly, the plasma and buffy coat were discarded following centrifugation $\left(8000 \mathrm{~g} \times 30 \mathrm{~min}\right.$ at $\left.4{ }^{\circ} \mathrm{C}\right)$ and the erythrocyte pellet was washed three times with normal saline solution (NSS). The erythrocytes were lysed overnight at $4{ }^{\circ} \mathrm{C}$ by adding an equal volume of sterile distilled water. The erythrocyte lysate was centrifuged at $8000 \mathrm{~g}$ for $30 \mathrm{~min}$ at $4{ }^{\circ} \mathrm{C}$. The pellet was washed once with NSS and centrifuged again. The sediment was resuspended in NSS, homogenised in a glass homogeniser and centrifuged until the haemoglobin was completely removed from the lysate pellet. The pellet was resuspended in an equal volume of cold NSS containing $1 \mathrm{mM}$ of phenylmethylsulfonyl fluoride (PMSF) and centrifuged at $800 \mathrm{~g}$ for $1 \mathrm{~min}$. The supernatant containing B. equi merozoites was collected, sonicated 8 times at $100 \mathrm{~W}$ for $30 \mathrm{~s}$ and was divided into two equal parts. One part was retained as the whole merozoite (WM) antigen. The second part was centrifuged at $145000 \mathrm{~g}$ for $1 \mathrm{~h}$ at $4{ }^{\circ} \mathrm{C}$. The supernatant was collected and designated as the high-speed supernatant (HSS) fraction. The sediment was collected separately, mixed with an equal volume of cold NSS containing $1 \mathrm{mM}$ PMSF, homogenised and designated the cell membrane (CM) fraction. The total protein concentration of these antigens was estimated by the method of Lowry et al. [21] and was expressed in $\mathrm{mg} / \mathrm{mL}$. All antigens were stored at $4{ }^{\circ} \mathrm{C}$.

\subsection{Reference sera}

In a previous study [19], four donkeys were experimentally infected with $B$. equi by intravenous injection of blood with a high parasitaemia $(\sim 70 \%)$. Serum samples were collected daily for the first 7 days post-infection (PI), then biweekly up to 40 days and finally once a week up to 89 days PI. Twenty-four (six samples from each four donkeys) serum samples with antibody titres ranging from low positive (1:200 to $1: 800$, representing samples collected during 1-10 days PI) to high positive (1:1600 to $1: 51200$, representing samples collected during 16 to 89 days PI) by Dot-ELISA were selected and used to standardise the serial and single dilution ELISAs. Another batch of 21 serum samples, collected from asymptomatic healthy donkeys (positive for the B. equi antibodies by Dot-ELISA) from different areas of the Haryana State, India, were selected and used in the present study to validate the titres obtained by serial dilution and single dilution ELISAs. Three reference negative control sera were collected from such donkeys, which had been repeatedly found negative for the $B$. equi parasite and antibodies by blood smear examination and Dot-ELISA, respectively. A reference B. caballi positive serum (1:80 CFT titre) was obtained from the United States Department of Agriculture (USDA), USA. Sera positive for Trypanosoma evansi, glanders, strangles, equine infectious anaemia and equine influenza were obtained from a laboratory testing clinically infected equids.

\subsection{Serological tests}

\subsubsection{Serial dilution ELISA}

The optimum dilution of the three antigens (WM, CM and HSS) and the conjugate [rabbit anti-horse gamma globulin (IgG) horse radish peroxidase, HRP, Sigma Aldrich Co., St. Louis, USA] were determined using a block titration method. 
The optimum dilution considered was the highest dilution of antigen/conjugate that gave a maximum contrast in terms of optical density (OD) between known positive and known negative serum dilutions. The technique described by Bose and Peymann [2] for B. caballi was adopted. Dilutions of 1:5, 1:10, 1:20 and 1:40 of the WM, CM and HSS antigens were prepared in $0.1 \mathrm{M}$ carbonate bicarbonate buffer, $\mathrm{pH} 9.6$ and $100 \mu \mathrm{L}$ of each dilution was used to coat the wells of a 96 well microtitre ELISA plate (Greiner, Germany). The plates were incubated at $37^{\circ} \mathrm{C}$ for $1 \mathrm{~h}$ and were kept at $4{ }^{\circ} \mathrm{C}$ overnight. These were then washed three times with PBS using an ELISA plate washer (Organon Teknika washer, Veedijk, 58, 2300, Turnhout, Belgium). The unoccupied sites in each well were blocked by adding $200 \mu \mathrm{L}$ of $3 \%$ bovine serum albumin (BSA) dissolved in PBS, pH 7.2 (PBS-3\% BSA) for $1 \mathrm{~h}$ at $37^{\circ} \mathrm{C}$. The plates were again washed three times with PBS and $100 \mu \mathrm{L}$ of two fold serum dilutions, from 1:50 to 1:51200 in PBS containing 1\% BSA (PBS-1\% BSA) were added to wells 1 to 11 in each row. Eight samples were loaded in each plate. The last (12th) column's wells of ELISA plate were used for controls, which included (a) a known positive sera; (b) a known negative sera; (c) serum + conjugate without antigen; (d) antigen + conjugate without serum; (e) antigen + serum + conjugate without substrate; (g) PBS alone and $(\mathrm{h})$ conjugate + substrate. The plates were incubated for $1 \mathrm{~h}$ at $37^{\circ} \mathrm{C}$, followed by washing with PBS- $0.05 \%$ Tween- 20 (PBS-T). Dilutions of the conjugate (1:500, 1:1000, 1:2000 and 1:4000) were prepared in PBS-1\% BSA. The desired dilution of the conjugate $(100 \mu \mathrm{L} /$ well $)$ was added to the appropriate wells and the plates were incubated for $1 \mathrm{~h}$ at $37^{\circ} \mathrm{C}$, followed by three more washes with PBS-T. Ortho-phenylene diamine dihydrochloride (OPD, Sigma) solution was prepared as per the manufacturer's instructions and $100 \mu \mathrm{L}$ dispensed into the wells except in well ' $e$ ' of control column 12. The plates were kept in the dark at room temperature for 20 $30 \mathrm{~min}$. On the development of a yellow colour and when the OD of the positive control well (h12) was $1.0-1.2,50 \mu \mathrm{L}$ of $2 \mathrm{M} \mathrm{H}_{2} \mathrm{SO}_{4}$ was added to each well to stop the enzymatic reaction. The plates were read at $492 \mathrm{~nm}$ in an ELISA plate reader (Organon Teknika Reader 530, Veedijk, 58, 2300, Turnhout, Belgium). The mean OD of the negative control wells (b12 to d12) was calculated. Any sample showing an OD above the mean $+(3 \times$ standard deviation) of three negative wells was considered positive. Standard deviation (SD) of the OD of three negative wells (b12 to d12) was calculated as per a standard procedure [29]. The highest dilution of the serum sample showing a positive reaction was recorded as the titre.

\subsubsection{Single dilution ELISA}

Regression analysis, as used by Briggs and Skeeles [3] and Manuja et al. [24] to predict the end point of antibody titres to Pasteurella multocida in chicken sera and Theileria annulata infection in bovine sera, respectively, was adopted.

The $\log _{10}$ end point antibody titres of 24 known positive $\left(\mathrm{y}_{\mathrm{i}}\right)$ and 3 known negative control sera were determined by diluting the sera from 1:50 to 1:51200 and using the three antigens viz; WM, CM and HSS separately by serial dilution ELISA. The mean OD values of the 24 known positive sera at 1:50, 1:100, 1:200, 1:400, 1:800 dilutions were divided by the mean OD of the three known negative serum samples at the respective dilution and were termed as positive/negative $(\mathrm{P} / \mathrm{N})$ ratios separately for each antigen. The coefficient of correlation (r) between the $\log _{10}$ end titre and the $\mathrm{P} / \mathrm{N}$ ratio (at serum dilutions of 1:50 to 1:800) was calculated separately for the three antigens as per the method described by Snedecor and Cochran [29]. The dilution of serum (1:50 to $1: 800)$ showing the maximum value of ' $r$ ' was chosen for the derivation of the regression equation $(\mathrm{y}=$ $a+b x$, where $y=\log _{10}$ antibody titre of the 
test serum, $\mathrm{x}=$ the $\mathrm{P} / \mathrm{N}$ ratio of the test serum at the chosen dilution, $\mathrm{a}=$ the constant and $b=$ the regression coefficient) for predicting $\log _{10}$ end titre by single dilution ELISA. The values of ' $a$ ' and ' $b$ ' were calculated separately for the three antigens (WM, CM and HSS), to have a unique regression equation for each antigen.

The test sera were diluted to the chosen dilution (which showed a maximum ' $\mathrm{r}$ ' value as described above) and were added into duplicate wells of ELISA plates coated separately with three different antigens. The assay was run as described under serial dilution ELISA and the OD was recorded at $492 \mathrm{~nm}$. The mean OD for each sample (recorded in three ELISA plates each coated with the WM or CM or HSS antigen) was converted to the $\mathrm{P} / \mathrm{N}$ ratio (x) and the $\log _{10}$ end antibody titres (y) were predicted by using the value of ' $\mathrm{x}$ ' in the regression equation separately derived for the three antigens.

\subsection{Validity of single dilution ELISA}

The antibody titres of 21 known positive field sera from $B$. equi antibody carrier donkeys were determined by serial dilution ELISA and were predicted by single dilution ELISA for the three antigens separately. The observed $\log _{10}$ antibody titres and predicted $\log _{10}$ antibody titres were compared for significance $(P<0.05)$ using factorial complete randomised design by ANOVA test and their coefficient of correlation was also calculated [29].

\subsection{Sensitivity, specificity, predictive value and cross-reactivity}

The statistical sensitivity, specificity and predictive value of single dilution ELISA with the three antigens were validated using the method described by Tyler and Cullor [31]. For this purpose, samples from the previously collected known B. equi disease-positive and disease-negative animals were used [19]. The protocol for this experiment is described in paragraph 2.2 of this article. Serum sam- ples were collected after the patency of B. equi parasitaemia (3 days PI onwards) in the four infected donkeys. Forty-two sera were selected (with at least 10 samples from each of the four donkeys) as diseasepositive samples. One-hundred and six sera were also collected simultaneously as $B$. equi disease-negative samples from 50 healthy donkeys that were reared in tick free housing facilities. These animals were found to be negative for the $B$. equi parasite by repeated blood smear examination and their sera were negative for antibodies by Dot-ELISA and the complement fixation test.

The immunological cross-reactivity of the $B$. equi antigens (WM, CM, HSS) with sera positive for B. caballi, Trypanosoma evansi, glanders, strangles, equine infectious anaemia and equine influenza were tested by performing serial dilution ELISA as standardised above using two fold serum dilutions from 1:50 to 1:51200. The immunological sensitivity was determined by serially diluting high titred $B$. equi positive serum and a negative serum (sera used as described in paragraph 2.2 reference sera) in serial dilution ELISA and by comparing the OD of the positive serum at a particular dilution with the OD of the negative serum.

\subsection{Unknown field sera}

The $\log _{10}$ end antibody titres of 109 field horse/donkey serum samples were determined by serial and single dilution ELISA in order to compare the sensitivity of these two ELISAs on unknown samples. Samples were obtained from different parts of the Haryana State, India.

\section{RESULTS}

\subsection{Optimum antigen and conjugate dilutions}

A dilution of 1:20, 1:20 and 1:5, respectively of the WM, CM and HSS antigens 


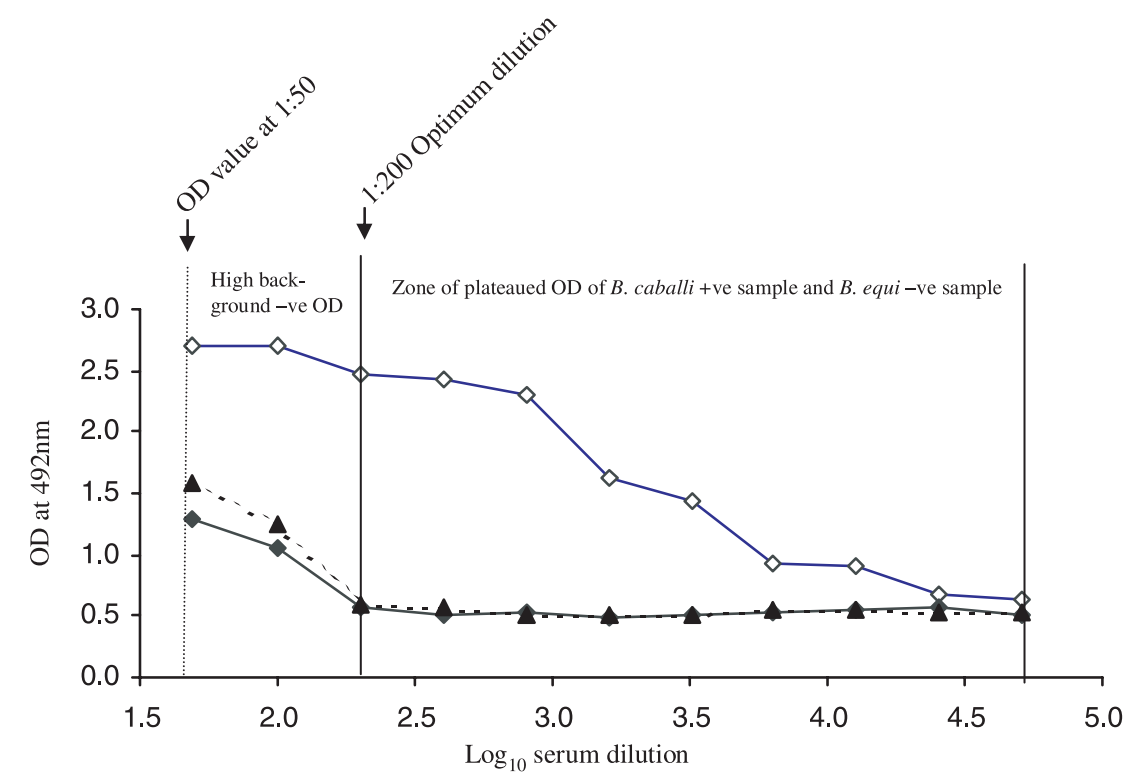

$ح$ Babesia equi positive serum

$\longrightarrow$ Babesia caballi positive serum

- . - . - . Babesia equi negative serum

Figure 1. Optical density of Babesia equi known positive, known negative and Babesia caballi known positive serum in serial dilution ELISA using the WM B. equi antigen.

proved optimum for the ELISA. The protein contents were $0.370,0.350$ and $0.500 \mathrm{mg} / \mathrm{mL}$ at the respective dilutions. The anti-horse HRP conjugated secondary antibody showed optimum results at a dilution of 1:1000. The optimum dilution of WM, CM and HSS antigens and conjugate, as standardised for the serial dilution ELISA, were also used for the single dilution ELISA.

\subsection{Serial dilution ELISA}

At a dilution of 1:200 $\left(\log _{10}\right.$ value $=$ 2.3) and above, the absorbance of the negative sera plateaued whereas, the positive sera continued to show a high absorbance value (Fig. 1). The observed reciprocal antibody end titre of 24 known positive serum samples was converted to the $\log _{10}$ value. Amongst the 24 samples tested, 15 showed a $\log _{10}$ antibody titre of 4.1 $(1: 12800)$ and above with the WM antigen whereas, 13 and 8 samples, respectively, showed a $\log _{10}$ antibody titre of 4.1 and above with the CM and HSS antigens (Fig. 2).

\subsubsection{Coefficient of correlation}

The coefficients of correlation ( $r$ ) between the $\log _{10}$ antibody titre of the 24 known positive sera with their respective $\mathrm{P} / \mathrm{N}$ ratios at 1:50, 1:100, 1:200, 1:400 and 1:800 are shown in Table I. The maximum value of ' $r$ ' was 0.938 and 0.943 observed at a serum dilution of 1:200 for the WM and HSS antigens, respectively. However with the CM antigen, the highest value of ' $r$ ' (0.977) was observed at a serum dilution of $1: 50$ followed by 0.974 at 1:200 dilution. But at the same time, known negative control sera also showed high OD values at 1:50 and 1:100 serum dilution (Fig. 1). Hence the 1:200 serum 


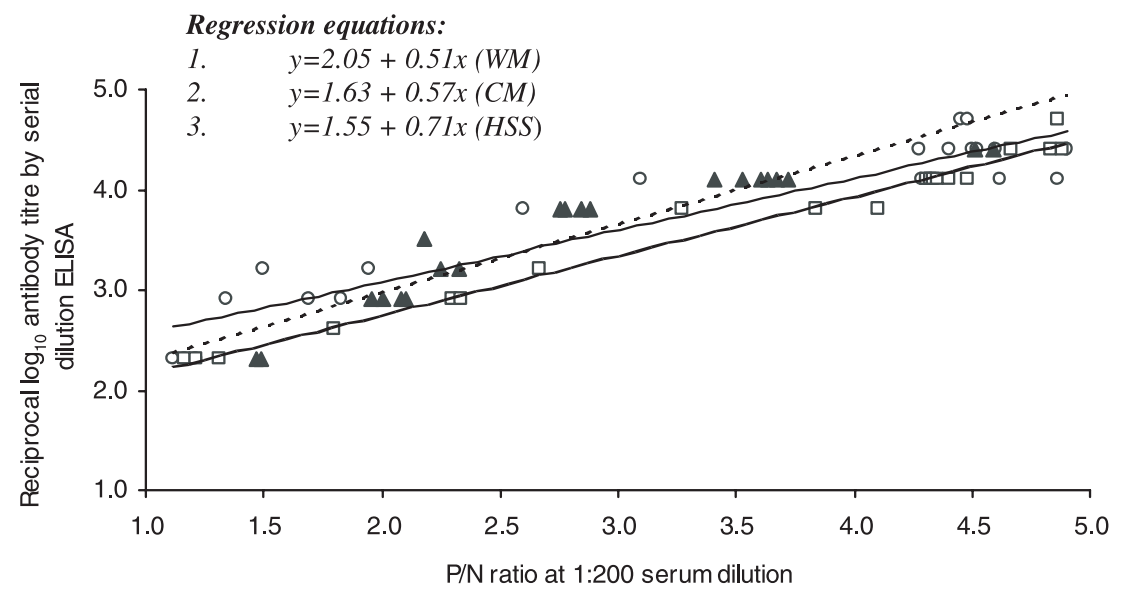

\begin{tabular}{|c|c|c|c|c|c|}
\hline$\circ$ & WM antigen & 口 & $\mathrm{CM}$ antigen & $\Delta$ & HSS antigen \\
\hline 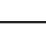 & Regression line (WM) & --- & - Regression line (CM) & $\ldots$. & Regression line (HSS) \\
\hline
\end{tabular}

Figure 2. Comparison of reciprocal $\log _{10}$ antibody titres obtained by serial dilution ELISA with the respective $\mathrm{P} / \mathrm{N}$ ratio at 1:200 serum dilutions.

dilution was considered most favourable for the CM antigen as well. So a 1:200 serum dilution was chosen for calculating the regression equation for each of the three antigens and also for testing of an unknown sample at only one dilution by single dilution ELISA for all three antigens.

\subsubsection{Regression equations}

The regression equations calculated for the three antigens were as follows:
1. WM antigen: $\mathrm{y}=2.05+0.51 \mathrm{x}$ (SE for ' $\mathrm{a}$ ' $=$ \pm 0.147 , SE for ' $\mathrm{b}$ ' $= \pm 0.041$ ).

2. CM antigen: $y=1.63+0.57 x$ (SE for ' $a$ ' $=$ \pm 0.073 , SE for ' $b$ ' $= \pm 0.020$ ).

3. HSS antigen: $y=1.55+0.71 \mathrm{x}(\mathrm{SE}$ for ' $\mathrm{a}$ ' $=$ \pm 0.164 , SE for ' $\mathrm{b}$ ' $= \pm 0.055$ ).

\subsubsection{Validity of the regression equations}

Reciprocal $\log _{10}$ antibody titres of the 21 sera observed by serial dilution ELISA did not differ significantly $(P>0.05)$ from

Table I. Coefficient of correlation between the positive/negative $(\mathrm{P} / \mathrm{N})$ ratio and reciprocal $\log _{10}$ end antibody observed titres by serial dilution ELISA at different two-fold dilutions of known positive control sera $(n=24)$.

\begin{tabular}{lccccc}
\hline \multirow{2}{*}{ Antigen } & \multicolumn{5}{c}{ Coefficient of correlation at respective serum dilution } \\
\cline { 2 - 5 } & $1: 50$ & $1: 100$ & $1: 200$ & $1: 400$ & $1: 800$ \\
\hline Whole merozoite (WM) & 0.931 & 0.934 & 0.938 & 0.915 & 0.931 \\
Cell membrane (CM) & 0.977 & 0.969 & 0.974 & 0.973 & 0.967 \\
High speed & 0.936 & 0.909 & 0.943 & 0.917 & 0.902 \\
supernatant (HSS) & & & & & \\
\hline
\end{tabular}




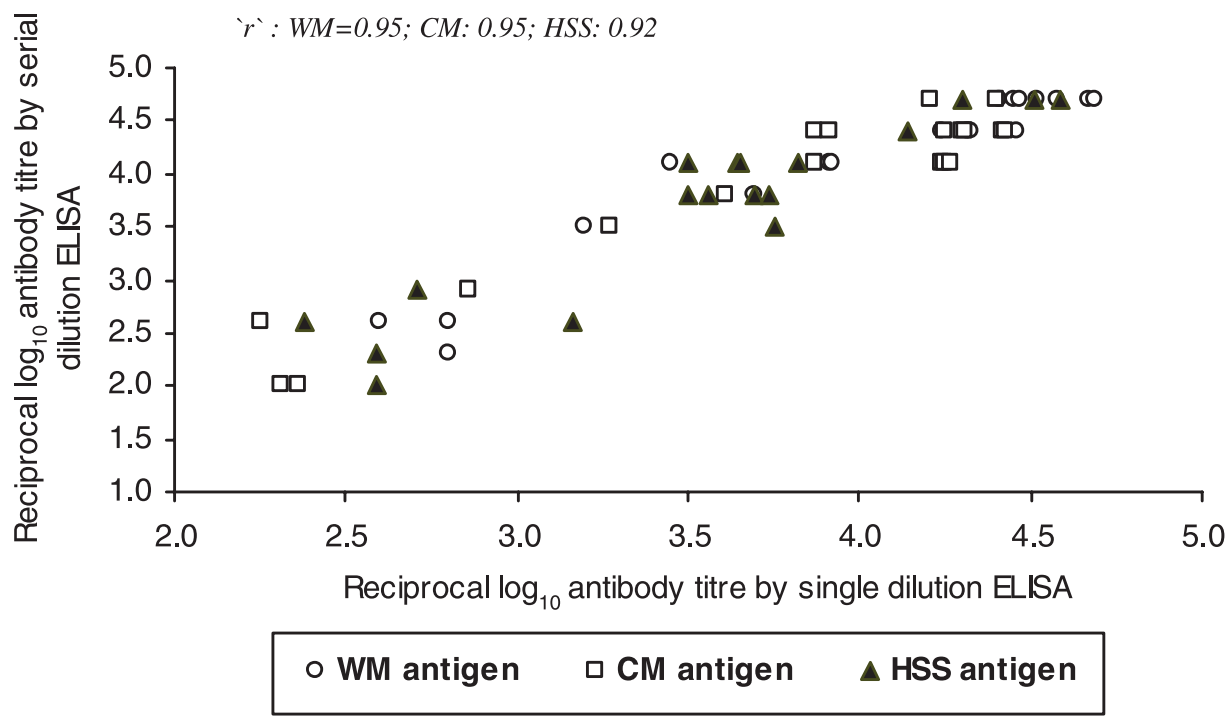

Figure 3. Comparison of $\log _{10}$ antibody titres observed and predicted by serial and single dilution ELISA, respectively using different Babesia equi antigenic preparations.

the corresponding predicted antibody titres obtained by single dilution ELISA for the WM, CM and HSS antigens, respectively. Furthermore, the antibody titres obtained by serial dilution and single dilution ELISA using WM, CM and HSS antigens showed very high coefficients of correlation (' $r$ ' $=0.95,0.95$ and 0.92 , respectively for the three antigens as shown in Fig. 3).

\subsection{Sensitivity, specificity, predictive value and cross-reaction}

As shown in Table II, the statistical specificity of the single dilution ELISA for detecting antibodies against $B$. equi was $100 \%$ with all three antigens, whereas, the sensitivity ranged from $80-88 \%$. The predictive value for positive sera was $100 \%$ and ranged from $93-95 \%$ for negative sera using the three antigens. The WM antigen was the most sensitive of the antigens and had the highest predictive value.
Known positive sera against $B$. caballi, Trypanosoma evansi, glanders, strangles, equine infectious anaemia and equine influenza did not show any cross-reactivity ( $<1: 50$ dilution) with the three B. equi antigens used in this study indicating the immunological specificity of the test. The OD of known B. caballi positive serum at 1:50, 1:100 and 1:200 dilution was lower than the mean OD of known negative sera (Fig. 1). ELISA was found to be very sensitive since positive OD values of a high titred B. equi serum were recorded up to a dilution of 1:51200 (Fig. 1).

\subsection{Unknown field sera}

A frequency distribution of antibody titres of 109 field sera tested by serial and single dilution ELISA using the WM antigen (Tab. III) shows that the results obtained using the two tests are comparable. The only difference was that two sera that were negative with serial dilution 
Table II. Sensitivity, specificity and predictive value efficacy of single dilution ELISA with WM, $\mathrm{CM}$ and HSS antigens.

\begin{tabular}{lccc}
\hline Parameters & WM antigen & CM antigen & HSS antigen \\
\hline Sensitivity $^{\mathrm{a}}(\%)$ & $88.0(37 / 42)$ & $86.0(36 / 42)$ & $81.0(34 / 42)$ \\
Specificity $^{\mathrm{b}}(\%)$ & $100.0(106 / 106)$ & $100.0(106 / 106)$ & $100.0(106 / 106)$ \\
Predictive value/positive test $^{\mathrm{c}}(\%)$ & 100.0 & 100.0 & 100.0 \\
Predictive value/negative test $^{\mathrm{d}}(\%)$ & 96.0 & 95.0 & 93.0 \\
\hline
\end{tabular}

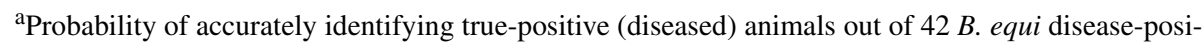
tive samples.

${ }^{\mathrm{b}}$ Probability of accurately identifying true-negative (normal) animals out of 106 B. equi disease-negative samples.

${ }^{c}$ Probability that ELISA-positive animals are B. equi disease-positive.

${ }^{\mathrm{d}}$ Probability that ELISA-negative animals are B. equi disease-negative.

Figures in parenthesis indicate the number of positive sera / total number of samples tested.

Table III. Frequency distribution of Babesia equi antibody titres as detected by serial dilution and single dilution ELISA on unknown equine sera collected from the field.

\begin{tabular}{lccl}
\hline $\begin{array}{l}\text { Reciprocal } \\
\text { antibody titre }\end{array}$ & \multicolumn{2}{c}{ No. of samples observed by } & \multicolumn{1}{c}{ Interpretation } \\
\cline { 2 - 3 } & $\begin{array}{c}\text { Serial dilution } \\
\text { ELISA }\end{array}$ & $\begin{array}{c}\text { Single dilution } \\
\text { ELISA }\end{array}$ & \\
\hline Up to 200 & 26 & 24 & - (Negative) \\
$201-800$ & 11 & 13 & + (Weakly positive) \\
$801-3200$ & 38 & 38 & ++ (Positive) \\
$3201-12800$ & 25 & 25 & +++ (High positive) \\
$>12800$ & 9 & 9 & ++++ (Very highly positive) \\
Total & 109 & 109 & \\
\hline
\end{tabular}

ELISA were detected as weak positives with the single dilution ELISA.

\section{DISCUSSION}

The commonly used CF test has to be combined with the IFA test for sero-diagnosis of $B$. equi antibodies in doubtful cases and this test has been demonstrated to lack the required specificity and sensitivity $[11,15,19]$. The conventional ELISA for sero-diagnosis of $B$. equi is cumbersome, time consuming and requires large quantities of reagents when the end titre of a sample is to be determined. However, the single dilution ELISA has been found to be cheaper, faster and reliable than conventional serial dilution ELISA as reported for other pathogens [17, 24]. Thus, the single dilution ELISA was developed to predict the B. equi antibody titre of a sample. Estimation of end antibody titre by single dilution ELISA could also be useful in monitoring the titres of passively transferred antibodies in young animals [8, 13]. The end antibody titres could also be important in deciding the effects of a drug against B. equi infection since antibody 
titres are reported to decline when $B$. equi carrier equids are treated $[16,32]$.

An advantage of the single dilution ELISA is that the exact antibody titre can be predicted since the colour change (OD) is directly proportional to the amount of antibody present. The $\mathrm{P} / \mathrm{N}$ ratio was used instead of the OD values at a particular dilution for standardisation of single dilution ELISA since a great variation in OD values for a particular sample is observed depending upon the assay conditions, time of incubation etc. However, the $\mathrm{P} / \mathrm{N}$ ratio for a particular serum sample at the same dilution remains relatively constant under varying test conditions, as reported previously for standardisation of similar tests for other pathogens [3, 24]. Regression equations as derived for use in single dilution ELISA, express the correlation between the two variables $\left(\log _{10}\right.$ end titre and $\mathrm{P} / \mathrm{N}$ ratio) and are necessary in predicting the value of the dependent variable $\left(\log _{10}\right.$ end titre) when the value of the independent variable $(\mathrm{P} / \mathrm{N}$ ratio) is known.

We tried in vitro cultivation of the B. equi parasite by the macroaerophilous stationary phase culture (MASP) technique $[15,35]$ for preparation of antigens but sufficient quantities of the parasite could not be propagated, hence the antigens were prepared from high parasitaemic blood collected from a splenectomised infected experimental donkey. The different antigens used, WM, CM and HSS represented the whole parasite, the cellular fraction and the soluble fraction, respectively [5]. The idea of using three antigen preparations in ELISA was to identify the best antigenic fraction which could be recommended for future use in ELISA. In ELISA, all three antigens detected antibodies against $B$. equi in test sera and the results were comparable: those samples showing low titres with the WM antigen also had low titres with the CM and HSS antigens. However, the WM antigen was found to be the most sensitive in the detec- tion of antibody titres. The sensitivity and predictive values for the negative tests were also greater when using the WM antigen as compared to the two other antigens. Furthermore, the WM antigen required less processing during preparation and was, therefore, the antigen of choice. This antigen was further used to compare the sensitivity of the serial dilution and single dilution ELISA with the unknown field serum samples.

No cross-reactions were observed with sera positive for B. caballi, Trypanosoma evansi, glanders, strangles, equine infectious anaemia or equine influenza with the three B. equi antigens in ELISA, indicating good immunological specificity of the standardised tests in the present study. Frerich et al. $[9,10]$ observed cross-reactivity of the $B$. equi antigen with $B$. caballi antiserum in CFT, while Weiland [32] reported cross-reactivity of two parasites in ELISA and not in CFT. Zwart and Broklesby [34] reported that the technique adopted for the preparation of the Babesia antigen was crucial and affected the specificity/cross-reactivity in the test. Furthermore Frerich et al. [9] observed a loss of specificity of the $B$. equi antigen if it was obtained after a number of serial needle passages among animals. Therefore, serial needle passages of the parasite were avoided in the present study and parasitaemia was boosted in the animal by splenectomy leading to immuno-suppression. Improvements in the techniques used for antigen preparation might have helped in reducing non-specific reactions.

Antigenic differences are known to exist between $B$. equi isolates from various regions [13]. Cross-reactions were observed when B. equi positive antigen/ serum of different origin (USDA and Brazilian) were used in IFAT. However, B. caballi positive serum from USDA, USA gave no cross-reaction with the $B$. equi antigen prepared from the parasite of Indian origin in the present study. We were not able to obtain B. caballi positive serum from equids of Indian origin since 
B. caballi has not been reported to be prevalent in India by using OIE [23] recommended serological and biological tests. It seems likely that the Indian isolate of B. equi might be antigenically different from the USDA strain. These observations at least support the fact that single dilution ELISA can be used with more confidence in countries such as India where $B$. caballi is not prevalent or large numbers of B. caballi positive animals are unlikely to be present.

Serum samples of known identity were deliberately selected from a previous study for the standardisation of serial and single dilution ELISA to increase the confidence of the regression equation so that unknown field sera with different antibody titres could be evaluated perfectly in this system. This was in conformity with earlier studies of Briggs and Skeeles [3]; Manuja et al. [24] and Khatri et al. [17], who adopted a similar strategy while standardising single dilution ELISA for detecting antibodies to other pathogens.

The analogy in antibody titres obtained by serial and single dilution ELISA revealed that the results obtained using the two tests were statistically similar and thus increased the confidence of the regression equation. This was also confirmed graphically (Fig. 3) by the close distribution of $\log _{10}$ antibody titres observed by the serial dilution ELISA and predicted by single dilution ELISA. Non-significant differences between the antibody titres of unknown field sera by serial and single dilution ELISA further validated the suitability of the single dilution ELISA for field surveys. These observations indicate that the test is immunologically and statistically specific and sensitive.

In the present study, the terms statistical sensitivity and statistical specificity indicate the probability of ELISA to accurately identify $B$. equi infected (true-positive) and non-infected (true-negative) animals, respectively. The predictive value of a positive test result indicates the probability that a test-positive (i.e. ELISA positive) animal really has the disease condition (B. equi infection). The immunological sensitivity of ELISA indicates the ability of the test to detect very low concentrations of antibodies in a positive sample (up to 1:51200 dilution in the present study, Fig. 1).

On the basis of this study, it can be concluded that the single dilution ELISA is as sensitive and specific as serial dilution ELISA in determining the end $B$. equi antibody titre of a serum sample. It is also more economical and less time consuming, since only one serum dilution is tested. Thus, single dilution ELISA using the WM antigen can be used in the field to detect antibodies to $B$. equi in test sera and is suitable for mass field epidemiological studies. To derive the regression equation, it is recommended that a statistically significant number of serum samples ranging from low to high titres should be used to validate each newly prepared batch of antigen.

\section{ACKNOWLEDGEMENTS}

The financial assistance provided to the first author by the Council of Scientific and Industrial Research (CSIR), New Delhi, in the form of Senior Research Fellowship and facilities provided by Dr. Y. Bhattacharyulu, former Project Coordinator of the All India Coordinated Research Project (AICRP) on Blood Protista, CCS HAU Hisar, India are gratefully acknowledged. Thanks are also due to Dr. D.R. Aneja Associate Professor, Statistics for guidance on statistical analysis.

\section{REFERENCES}

[1] Beniwal R.P., Nichani A.K., Rakha N.K., Sharma R.D., Sarup S., An immunisation trial with in-vitro produced Babesia bigemina exoantigens, Trop. Anim. Health Prod. 29 (1997) 124S-126S.

[2] Bose R., Peymann B., Diagnosis of Babesia caballi infections in horse by enzyme-linked immunosorbent assay (ELISA) and western blot, Int. J. Parasitol. 24 (1994) 347-356.

[3] Briggs D.J., Skeeles J.K., An enzyme-linked immunosorbant assay for detecting 
antibodies to Pasteurella multocida in chickens, Avian Dis. 28 (1984) 208-215.

[4] Brooks L.M., The equine piroplasmosis control programme at the 1996 Summer Olympic Games. Equine Infectious Diseases VIII. Proceedings of the Eighth International Conference, Dubai, 1998, pp. 371-375.

[5] Brown W.C., Kathleen S.L., Gerald G.W., Tetzlaff C.L., Cell mediated immune response to Babesia equi merozoite antigen in cattle following infection with tick-derived or cultured parasite, Infect. Immun. 59 (1991) 2418-2426.

[6] Bruning A., Phipps P., Posnett E., Canning E.U., Monoclonal antibodies against Babesia caballi and Babesia equi and their application in serodiagnosis, Vet. Parasitol. 68 (1997) 11-26.

[7] Dennig H.K., Brocklesby D.W., Splenectomy of horses and donkeys, Vet. Rec. 77 (1965) 40-45.

[8] Donnelly J., Phipps L.P., Evidence of maternal antibodies to Babesia equi and Babesia caballi in foals of seropositive mares, Equine Vet. J. 14 (1982) 126-128.

[9] Frerich W.M., Holbrook A.A., Johnson A.J., Equine piroplasmosis: complement-fixation titres of horses infected with Babesia caballi, Am. J. Vet. Res. 30 (1969) 697-702.

[10] Frerich W.M., Holbrook A.A., Johnson A.J., Equine piroplasmosis: production of antigens for the complement-fixation test, Am. J. Vet. Res. 30 (1969) 1337-1341.

[11] Friedhoff K.T., Soule C., An account on equine babesiosis, Rev. Sci. Tech. Off. Int. Epizoot. 15 (1996) 1191-1201.

[12] Gautam O.P., Dwivedi S.K., Equine babesiosis: A severe out-break in a stud farm at Hissar, Indian Vet. J. 53 (1976) 546-551.

[13] Heuchert C.M.S., de Giulli Jr. V., de Athaide D.F., Bose R., Friedhoff K.T., Seroepidemiology studies on Babesia equi and Babesia caballi infections in Brazil, Vet. Parasitol. 85 (1999) 1-11.

[14] Hirato K., Ninomiya M., Uwano Y., Kuth T., Studies on the complement-fixation reaction for equine piroplasmosis, Jpn. J. Vet. Sci. 7 (1945) 197-205.

[15] Holman P.J., Chieves L., Frerichs W.M., Olson D., Wagner G.G., Culture confirmation of the carrier status of Babesia equi infected horses, J. Clin. Microbiol. 31 (1993) 698-701.

[16] Kerber C.E., Ferreira F., Pereira M.C., Efficacy of imidocarb against natural Babesia equi infections in horses. Equine Infectious Diseases VIII. Proceedings of the Eighth International Conference, Dubai, 1998, pp. $552-554$
[17] Khatri N., Nichani A.K., Sharma R.D., Khatri M., Malhotra D.V., Effect of vaccination on young calves born during winter season in the field with the Theileria annulata (Hisar) cell culture vaccine, Vet. Res. Commun. 25 (2001) 179-188.

[18] Knowles D.P., Perryman L.E., Goff W.L., Miller C.D., Harrington R.D., Gorham J.R., A monoclonal antibody defines a geographically conserved surface protein epitope of Babesia equi merozoites, Infect. Immun. 59 (1991) 2412-2417.

[19] Kumar S., Malhotra D.V., Dhar S., Serodiagnosis of Babesia equi infection - a comparison of Dot-ELISA, complement fixation test and capillary tube agglutination test, Vet. Parasitol. 69 (1997) 171-176.

[20] Levine N.D., in: Veterinary Protozoology, Iowa State University Press, Ames, Iowa, 1985.

[21] Lowry O.H., Rosebrough N.J., Farr A., Randall R.J., Protein estimation with the Folin Phenol reagent, J. Biol. Chem. 195 (1951) 265-275.

[22] Madden P.A., Holbrook A.A., Equine piroplasmosis: indirect fluorescent antibody test for Babesia caballi, Am. J. Vet. Res. 29 (1968) 117-119.

[23] Manual of recommended diagnostic techniques and requirements for biological products for lists A and B diseases, Office International Des Epizooties, Vol. I, 1989, 1/6-6/6.

[24] Manuja A., Nichani A.K., Kumar R., Sharma R.D., Kumar B., Single dilution ELISAs using piroplasm, cellular schizont and soluble schizont antigens for the detection of antibodies against Theileria annulata, Vet. Res. 32 (2001) 165-173.

[25] Mc Guire T.C., Van Hoosier G.L., Henson J.B., The complement-fixation reaction in equine infectious anaemia demonstration of inhibition by $\operatorname{IgG}(\mathrm{T})$, J. Immunol. 107 (1971) 1738-1744.

[26] Sharma R.D., Gautam O.P., Clinical cases of equine babesiosis, Haryana Vet. XVI (1977) 19-26.

[27] Sharma R.D., Tanwar R.K., Gahlot A.K. Yadav J.S., Rajvanshi D.S., Note on clinical studies in Babesia equi infection in ponies, Indian J. Anim. Sci. 52 (1982) 1001-1003.

[28] Singh S., Khatri N., Manuja A., Sharma R.D., Malhotra D.V., Nichani A.K., Impact of field vaccination with a Theileria annulata schizont cell culture vaccine on the epidemiology of tropical theileriosis, Vet. Parasitol. 101 (2001) 91-100.

[29] Snedecor G.W., Cochra W.G., Statistical Methods, 8th Edition Iowa University Press, Ames, Iowa, 1989. 
[30] Tenter A.M., Friedhoff K.T., Serodiagnosis of experimental and natural Babesia equi and Babesia caballi infections, Vet. Parasitol. 20 (1986) 49-61.

[31] Tyler J.M., Cullor J.S., Titers, tests, and truisms: rational interpretation of diagnostic serological testing, J. Am. Vet. Med. Assoc. 194 (1989) 1550-1558.

[32] Weiland G., Species-specific serodiagnosis of equine piroplasmosis infections by means of complement fixation test, immunofluorescence and enzyme-linked immunosorbant assay, Vet. Parasitol. 20 (1986) 43-48.
[33] Westbury H.A., Chamnanpood P., Tangchaitrong S., Doughty W.J., Single dilution ELISA for detection of serum antibody to foot-and-mouth disease virus in cattle, Vet. Microbiol. 18 (1988) 273-283.

[34] Zwart D., Brocklesby D.W., Babesiosis: Non-specific resistance, immunological factors and pathogenesis, Adv. Parasitol. (1979) 49-113.

[35] Zweygarth E, Just M.C., Waal D.T., Continuous in vitro cultivation of erythrocytic stages of Babesia equi, Parasitol. Res. 81 (1995) 355-358. 
